\title{
The Effects of Bio-inspired Electromagnetic Fields on Healthy Enhancement with Case Studies
}

\author{
Shujun Zhang ${ }^{\text {a,c*}}$, Michael Clark ${ }^{\mathrm{b}}$, Xuelei Liu ${ }^{\mathrm{c}}$, Donghui Chen ${ }^{\mathrm{c}}$, Paula Thomas ${ }^{\mathrm{a}}$, \\ Luquan Ren ${ }^{\mathrm{c}}$ \\ ${ }^{a}$ School of Computing and Technology, University of Gloucestershire, The Park, Cheltenham, GL50 2RH, UK \\ ${ }^{b}$ Magnacare Health Group, 20-22 Pemberton Street, Birmingham, B18 6NY, UK
}

${ }^{c}$ Key Laboratory of Bionic Engineering (Ministry of Education), College of Biological and Agricultural Engineering, Jilin University, Changchun, 130022, China

\begin{abstract}
In this paper, an innovative bionic system will be presented. This system can be used to generate bioinspired electromagnetic fields (BIEFM) by mimicking natural Earth magnetic fields, the frequencies, strengths and waveforms of body organs and cellular pulsations. The preliminary tests have been carried out to investigate the influences of BIEFM on the ATP levels of people to prove the interactions between BIEMF and the cellular level's bio-processing activities. This system has been applied for the health enhancement of humans and pets etc. A number of case studies will be present to demonstrate the efficiency and effectiveness of the system. The case study experimental results have shown that this innovative bio-inspired system works efficiently and effectively in enhancing human and animal health. It has been proven that this bio-inspired system can be effectively applied to many areas such as (1) human health enhancement and illness treatment, (2) pet health enhancement, and (3) reduction or elimination of 'jet lag'.
\end{abstract}

\section{Keywords:}

Bionics System;

Health Enhancement;

Bio-inspired Electromagnetic Fields
Article History:

Received: 12 September 2019

Accepted: 19 November 2019

Published: $01 \quad$ December 2019

\section{1- Introduction}

It is believed that the health of our body is totally dependent on the health of our cells. We are in essence, cellular beings. Our 100 trillion cells intelligently communicate with each other at faster than light speed creating some 400 billion reactions every second which involve over 100,000 bio-molecules. The cell is the basic structural, functional and biological unit of all known living organisms. Cells consist of cytoplasm enclosed within a membrane. The membrane of a cell pulses at certain frequency with certain magnitudes [1-9]. More the cell pulse is, the more active and energetic the cells are and the higher the cell health. Besides, our human and other animals lives in the environment on the earth with the extremely low natural frequencies (ELF) that the earth produces both high in the atmosphere (Schumann $(7.83 \mathrm{~Hz}))$ as well as on and below the planet's surface (Geomagnetic $(10 \mathrm{~Hz})$ ) [10]. Schumann and Geomagnetic frequencies are vital to the wellbeing of all living things. It is believed that if we are in an environment with bio-inspired electromagnetic signals generated by mimicking natural earth magnetic fields and the frequencies, magnitudes and waveforms of the body and cell pulsations, then our cells will be more energetic and active, so we are healthier.

There have been many reports about the influences of electromagnetic fields on healthy conditions of human beings [11-23]. However, most of the previous research have been focused on electromagnetic fields of wide range of frequencies and magnitudes. There have been limited reports on bio-inspired electromagnetic field and its effects on

\footnotetext{
* CONTACT: Szhang@glos.ac.uk

DOI: http://dx.doi.org/10.28991/esj-2019-01199
}

(C) 2019 by the authors. Licensee ESJ, Italy. This is an open access article under the terms and conditions of the Creative Commons Attribution (CC-BY) license (https://creativecommons.org/licenses/by/4.0/). 
cells and health of human beings and animals. So it is necessary to investigate how to produce electromagnetic fields by mimicking natural earth magnetic fields and the frequencies, magnitudes and waveforms of the body organs and cell pulsations and their effects on cells, human being and animals. In addition, most previous work is based on the effective observations of the healthy enhancement, there are few scientific reports for verifying the direct influences of BIEFM on the cellular bio-processing activity.

Following introduction, Section 2 discusses natural electromagnetic fields and its bio-inspirations for the bionic system design for generating pulsed electromagnetic fields, Section 3 presents the design, functions and the applications of an innovative bio-inspired electromagnetic field system, Section 4 provides the scientific findings from the tests of the effects of BIEFM on ATP level with purpose of demonstrating that BIEFM does have the direct influence on the cellular bio-processing activities and Section 5 presents a number of case studies. Section 6 draws the conclusions and discussion of the limitation of the study and suggestions for the future research.

\section{2- Natural Electromagnetic Fields}

Lipkova and Cechak found that human electromagnetic emission is in the extremely low frequencies (ELF) band [9]. Though a cell measures about 10 microns, i.e. $10-5 \mathrm{~m}$, it is still enormous to compare with particles carrying electrical charge (electrons) - there is place for at least 10,000 for them on the cell length and about 30,000 for them on the cell circumference. Cell interior is negative in respect to its surface and potential across the plasmatic cell membrane is reaching values between $-20 \mathrm{mV}$ and $-200 \mathrm{mV}$. resting membrane potential (RMP) of the nerve cell is in range $-40 \mathrm{mV}$ to $-90 \mathrm{mV}$, the sustained value is $-70 \mathrm{mV}$. Aforesaid voltage values are really negligible; currents reach orders of magnitude of microamperes. Nevertheless, those values are not insignificant. Their experiment results shows that man is emitting electromagnetic energy in the frequency range of $0.5-30 \mathrm{~Hz}$ and the currents in orders of magnitude of microamperes [9]. There were harmonic components on frequencies of $2 \mathrm{~Hz}, 3 \mathrm{~Hz}, 4.2 \mathrm{~Hz}, 16.8 \mathrm{~Hz}$ and $21.3 \mathrm{~Hz}$, incidental with the cardiac, breathing and cerebral functions in humans. As discussed above, the earth produces both high in the atmosphere (Schumann $(7.83 \mathrm{~Hz})$ ) as well as on and below the planet's surface (Geomagnetic (10 Hz)) [10].

Above scientific studies shows that (1) potential across the plasmatic cell membrane is reaching values between -20 $\mathrm{mV}$ and $-200 \mathrm{mV}$, (2) man is emitting electromagnetic energy in the band of interest, deliberately to the frequency interval of $0.5-30 \mathrm{~Hz}$, within which, Schumann resonance of $7.83 \mathrm{~Hz}$ is.

These findings provide the bio-inspirations and motivation to design and develop an equipment that can be used to generate the similar electromagnetic fields by mimicking cell's pulse frequency, magnitudes and waveforms.

\section{3- An Innovative Bio-inspired Electromagnetic Field System}

\section{3-1- An Introduction to Magnetic Resonance Induction Therapy}

Magnetic therapy is not a modern discovery. It was widely used by the Ancient Egyptians, Ancient Chinese and the Ancient Greeks. In 1773, Franz Mesmer began using magnets for healing. By 1884, about 10,000 physicians in the USA were successfully using various magnetic devices every day for therapeutic purpose. In 1900, a wide variety of therapeutic magnetic devices were offered to the public by Sears and other catalogues. In 1924, the Nobel Prize was awarded to W. Einthoven for the discovery of the heart's electrical nature. In 1929 Hans Berger discovered the brain produces a magnetic field of $7.83 \mathrm{~Hz}$, which led to another ground-breaking invention in medicine: The Electroencephalogram or EEG. In 1963 Bale and McFee discovered that the heart produces a magnetic field which is not surprising as electric current always produces a magnetic field. In the USA doctors applied this discovery and saved lives every day by using the newly discovered Electrocardiogram. The latest discoveries show that each organ in the body has its own electromagnetic field and that this field covers the whole body. In Europe magnetic devices are used by private practices and in hospitals to speed up the healing process and to speed up recovery. We are subjected to magnetic effects in the environment every day of our lives and by our own magnetic energies generated at the cellular level and beyond. A force field of magnetic energy is created whenever a charged particle (e.g. an electron) moves. When billions of these electrons and other charged particles in your body move a multi-potential effect is exerted on us as a biological system. This effect is used by the Magnafield ${ }^{\circ}$ unit in a positive way to assist in healing.

\section{3-2- The Magnafield® and Magnapulse Development Background}

Numerous types of electro-medical therapy systems for the treatment of injuries and painful conditions both in humans and in animals have been developed over recent years. Amongst these, Magnetic field therapy has been in use in the medical profession for over 60 years [14, 15, 18, 20, 23, 24]. Recent worldwide research into the effects of magnetic energy on body tissue has resulted in a clearer understanding of how and why magnetism plays such an important role in the balanced operation of every cell in the body. We have natural magnetic emanations from the earth itself at close to $10 \mathrm{~Hz}$ and the outer orbit Schumann resonance at 7.83 to $7.96 \mathrm{~Hz}$ both of which have a subtle but critical effect on all living matter [9]. The last 18 years have seen several types of electro-magnetic therapy units come onto the market. Most of these utilise 'direct, 'uni-directional' or 'alternating' modes of operation. All of these types have some 
benefit and have been used by clinics, hospitals and in the home. But there are various issues associated with most of the existing units: some of them employ high frequency and amplitude signals, so that these kinds of units can only use a short time a day; some of them use man-made signals so that the effectiveness of the units vary significantly. It is difficult for the users to use them in reliable and safe way;

Magnafield ${ }^{\circledR}$ and Magnapulse, a technology with extensive research and testing behind them, is one of the most advanced and effective units available. It has been successfully used in many situations and in many different countries.

\section{3-3- System Design of the Magnafield ${ }^{\circledR}$}

The Magnafield ${ }^{\circledR}$ was designed and developed by mimicking natural electromagnetic fields, as discussed in Section 2. The Magnafield mainly consists of (1) computer micro-processor for control the system, (2) signal generation unit that can produce bio-inspired electromagnetic fields in $\mathrm{mV}$ and $\mathrm{mA}$ with frequency range of $0.5 \mathrm{~Hz}-18 \mathrm{~Hz}$. There is one specific frequency at $7.83 \mathrm{~Hz}$ to mimic Schumann resonance and (3) output coil. The system specifications is listed in Table 1. Figure 1 shows the approximate shape of the predominant enclosed electromagnetic fields from Magnafield® when the frequency is at $12 \mathrm{~Hz}$.

Table 1. System specifications of Magnafield ${ }^{\circledR}$.

\begin{tabular}{cccc}
\hline Model & MF2200 & Induction & $\mathbf{0 . 4 m V ~ @ < 0 . 2 \mu T}$ \\
\hline Input & $120 \mathrm{~V} / 240 \mathrm{~V} \mathrm{AC}+/-10 \% ; 50 / 60 \mathrm{~Hz} @ 0.1 \mathrm{Amp}$ & Induced Current & In the micro Ampere range \\
\hline Fuse & $2 \times 20 \mathrm{~mm} 5 \mathrm{Amp} \mathrm{M} 205 \mathrm{Time}$ Delay & Frequencies & 11 selectable in the range $0.5 \mathrm{~Hz}-18 \mathrm{~Hz}$ \\
\hline Output & Pulsed 18V AC (13V rms) & Timers & 20 minute standard duration \\
\hline $\begin{array}{l}\text { Power } \\
\text { Biological } \\
\text { waveform }\end{array}$ & 10W pulsed, driving output coil & Repeat Mode & 20 minutes on followed by 20 minutes off then repeated \\
until switched off.
\end{tabular}

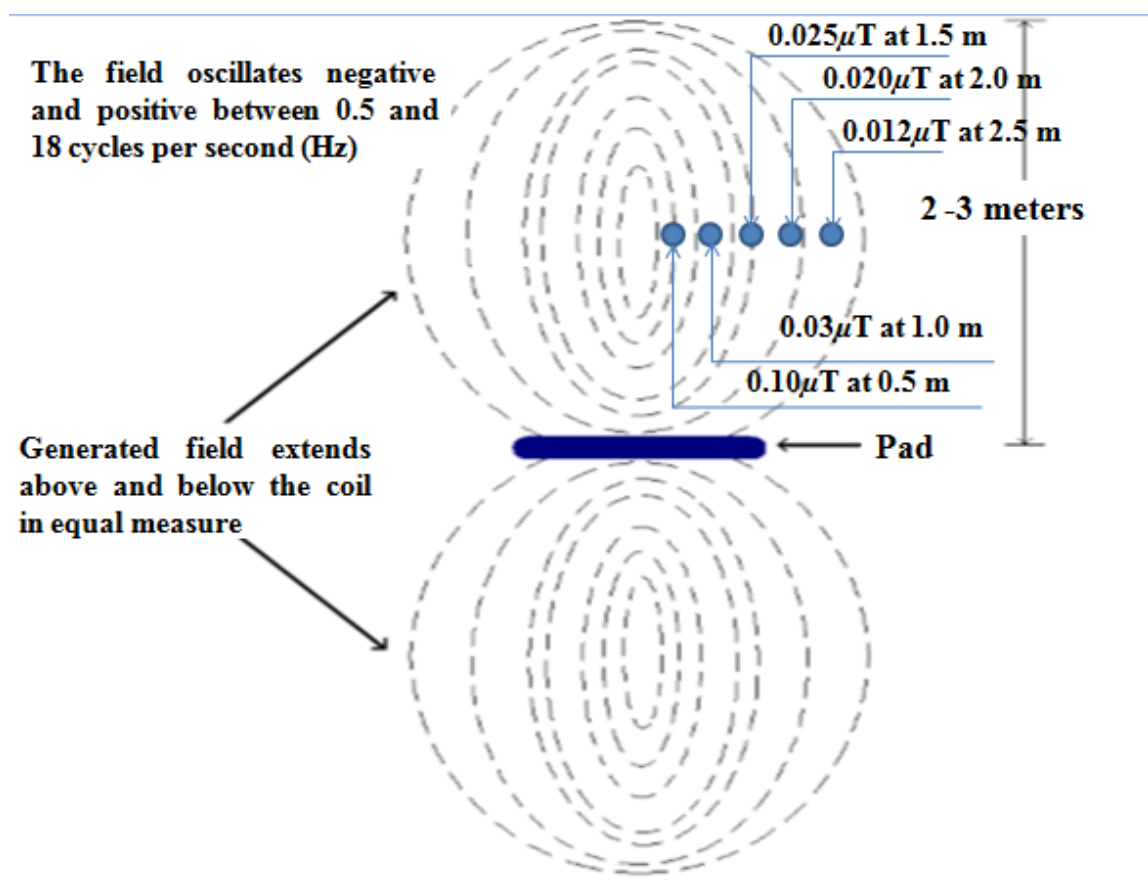

Figure 1. The approximate shape of the predominant enclosed electromagnetic fields when the frequency is at $12 \mathrm{~Hz}$.

The strength of the bio-inspired electromagnetic fields is listed in Table 2.

Table 2. The strength of the signals.

\begin{tabular}{ccccc}
\hline Frequency & $\mathbf{0 . 5 H z}$ & $\mathbf{8 H z}$ & $\mathbf{1 2 H z}$ & Range \\
\hline & $0.05 \mu \mathrm{T}$ & $0.07 \mu \mathrm{T}$ & $0.10 \mu \mathrm{T}$ & $50 \mathrm{~cm}$ \\
The strength of bio-inspired & $0.04 \mu \mathrm{T}$ & $0.06 \mu \mathrm{T}$ & $0.03 \mu \mathrm{T}$ & $100 \mathrm{~cm}$ \\
electromagnetic fields & $0.025 \mu \mathrm{T}$ & $0.028 \mu \mathrm{T}$ & $0.025 \mu \mathrm{T}$ & $150 \mathrm{~cm}$ \\
& $0.010 \mu \mathrm{T}$ & $0.015 \mu \mathrm{T}$ & $0.020 \mu \mathrm{T}$ & $200 \mathrm{~cm}$ \\
& $0.006 \mu \mathrm{T}$ & $0.008 \mu \mathrm{T}$ & $0.012 \mu \mathrm{T}$ & $250 \mathrm{~cm}$ \\
\hline
\end{tabular}




\section{3-4- Observed Magnafield ${ }^{\circledR}$ Effects}

Magnafield $®$ successfully uses extremely low frequency, low power multiple form pulses. The oscillating electromagnetic forces work in conjunction with a group of specific harmonics which are introduced through the body subjecting nerve and other cell tissue to changing electrical potentials which induce an analgesic effect and promote the healing of damaged tissue. The main effect of Magnafield $®$ is at the cellular level.

The general effects of the Magnafield $®$ are:

- Ionic transfer - calcium, potassium, and sodium balanced may be restored (Essential for normal cell function \& health);

- Protein synthesis may be increased and absorption rate can be increased (Cellular uptake providing healthy tissue and muscle elasticity);

- Acid/alkaline pH balance may be improved, particularly if too acidic (May assist with digestion; also helps with some arthritic conditions);

- Inflammation, swelling and pain may be reduced at $0.05 \mathrm{~Hz}$ to $3 \mathrm{~Hz}$ (Temporary Relief) (Important phase prior to promotion of the healing process);

- Cell regeneration and healing may be assisted: Oxygen transport and cellular uptake improved at $5 \mathrm{~Hz}, 8 \mathrm{~Hz}$ and $10 \mathrm{~Hz}$ (Helps to promote good health);

- Blood flow, peripheral circulation may be enhanced (Especially at $12-15 \mathrm{~Hz}$ ) (May improve peripheral circulation, healing rate and reduce risk of more serious injury);

- Phagocyte cell production, T-cell and auto-immune system stimulation $(0.5,4$ and $8 \mathrm{~Hz})$ (For health maintenance and improvement);

- Endorphin, encephalin, serotonin and nor-adrenaline release for pain inhibition (Stimulating the body's own natural pain inhibitors - temporary relief);

- Synchronisation of dominant brain waves $(0.5,1$ and $10 \mathrm{~Hz})$ (Assists with co-ordination and balance).

Another distinctive feature Magnafield $\AA$ is its 'Repeat Function'. Magnafield $₫$ is the only electromagnetic field equipment that can be applied repeatedly and continuously without stop. Apart from single treatments in some clinical situations it is advisable to have repetitive multiple applications. The Magnafield® will do this automatically. The Magnafield@ ${ }^{\circledR}$ will automatically operate for 20 minutes (the timer display will count down). At the end of the 20 minute treatment period, the Magnafield $®$ unit will stop for 20 minutes resuming treatment at the end of the rest interval. This cycle of 20 minutes on and 20 minutes off will continue until the unit is stopped.

\section{3-5- Frequency - the Key to Effective Treatment}

It is recognised that the specific nature of the electromagnetic signals natural to the normal operation of the body. These are characterised by ultra-low frequency, low power, oscillating signals with a group of associated, specific harmonics.

In addressing any condition with the Magnafield ${ }^{\circledR}$ the frequency selection is the most important factor. In general, the following is a guide to the possible effects at various frequencies.

Generally under 10Hz: There can be a mild vaso-constrictive effect, increased lymph drainage effect, blood flow, inflammation, metabolism reduced or lowered;

At 10Hz: Stabilising (re-balancing effect) liver function may be assisted;

Over 10Hz: Mild vaso-dilative effect, assisted blood flow increase and cellular activity and metabolism increase.

Some specific frequencies are reported to have the following effects as listed in Table 3.

Table 3. The effect of Magnafield ${ }^{\circledR}$ at some specific frequencies.

\begin{tabular}{ll}
\hline Frequency & Effects \\
\hline $0.5 \mathrm{~Hz}-4 \mathrm{~Hz}$ & $\begin{array}{l}\text { Sedating, relaxing and calming effect; assists with deeper sleep. Reduction of bruising, bleeding. Lymph drainage (micro- } \\
\text { muscular movement), best at 3Hz or 1Hz, pain relief (temporary). }\end{array}$ \\
\hline $0.5 \mathrm{~Hz}-1 \mathrm{~Hz}$ & $\begin{array}{l}\text { Pain relief (Temporary) - natural opiates released; lymphatic's assisted. Reported mitosis reduction or inhibition of rogue cell } \\
\text { activity, oxygen absorption. } \bullet \text { Balancing sodium-potassium cellular exchange; improved neurological signalling. }\end{array}$ \\
\hline $2 \mathrm{~Hz}$ & Promotes phagocyte and T-cell production. $\bullet$ Reported stimulation of the immune system (Thymus). \\
\hline $3 \mathrm{~Hz}$ & Assist lymph drainage; also good for sleep where $0.5 \mathrm{~Hz}$ is not benefitting. \\
\hline
\end{tabular}




\begin{tabular}{ll}
\hline $4 \mathrm{~Hz}$ & Pain modulation (temporary relief) if $0.5 \mathrm{~Hz}$ or $1 \mathrm{~Hz}$ are not helping. \\
\hline $5 \mathrm{~Hz}$ & Increased DNA synthesis; cellular signalling; repair and healing. \\
\hline $8 \mathrm{~Hz}$ & $\begin{array}{l}\text { Muscle tissue repair; muscle tone; nerve regeneration. } \bullet \text { Stimulation of ATP production. } \bullet \text { Recharging and balancing of ionic } \\
\text { and cell membrane potentials. }\end{array}$ \\
\hline $10 \mathrm{~Hz}$ & General re-balancing of cellular activity; improved oxygen uptake; assists liver function. \\
\hline $12 \mathrm{~Hz}-15 \mathrm{~Hz}$ & May assist in peripheral circulation; Increased blood flow through vasculature relaxation; more oxygen and nutrients available. \\
\hline $18 \mathrm{~Hz}$ & Increased metabolic rate; pre-sport or pre-exercise (for generally healthy people).
\end{tabular}

In addition, it should be pointed out that the Magnafield ${ }^{\circledR}$ unit incorporates the preceding properties in its induced field. The Magnafield ${ }^{\circledR}$ unit was the first to reflect the added benefits gained at $1 \mathrm{~Hz}-5 \mathrm{~Hz}$. The unit had another world first with the introduction and successful utilisation of $0.5 \mathrm{~Hz}$ oscillating pulses. The $0.5 \mathrm{~Hz}$ pulsed frequency is a special feature of the Magnafield $\AA$. This lower frequency offers the greater benefits of low frequency biological and bioenergetic electromagnetic induction.

All 11 frequencies promote tissue repair and there are no known or reported side effects of the Magnafield®.

In summary, the Magnafield ${ }^{\circledR}$ operates at the cellular level and beyond in an effort to assist the body to heal itself from the inside. Individual disease states and conditions are not normally subject to this approach. The intent is to make every cell of your body a healthy cell and by doing so equip your own body with the means to combat disease. In Section 4 , the tests have been carried out to investigate the effects of BIEFM on human ATP levels with purpose of proving that BIEMF do have the direct influence on cellular level's bio-processing activities.

\section{4- ATP Tests}

\section{4-1- ATP and its Generations}

All cells in the body need Calcium, Oxygen, Glucose, Potassium and Magnesium etc., to correctly function. Calcium, Oxygen and Glucose are essential for the production of ATP (Adenosine Triphosphate). ATP is the basic 'fuel' needed to drive the mitochondria that are the cells' main energy producers. So it is vital that cells are able to produce enough ATP.

Mitochondria produce energy for the cell. Mitochondria are self-replicating organelles. Cellular respiration occurs in the cell mitochondria. This set of metabolic reactions and processes converts biochemical energy from nutrients (by oxidative phosphorylation, using oxygen to release energy stored in cellular nutrients, typically pertaining to glucose, into (ATP), and then release waste products. Nutrients that are commonly used by animal and plant cells in respiration include sugar, amino acids and fatty acids, and the most common oxidizing agent (electron acceptor) is molecular oxygen $\left(\mathrm{O}_{2}\right)$. It is theoretically believed that 38 ATP molecules can be made per oxidised glucose molecule during cellular respiration ( 2 from glycolysis, 2 from the Krebs cycle, and about 34 from the electron transport system ). However, this maximum yield is never quite reached because of losses due to leaky membranes as well as the cost of moving pyruvate and ADP into the mitochondrial matrix, and current estimates range around 29 to 30 ATP per glucose [25].

ATP is produced and consumed in cells as a coenzyme often called the "molecular unit of currency" of intracellular energy transfer [26]. ATP transports chemical energy within cells for metabolism. ATP is generated through photophosphorylation, aerobic respiration, and fermentation. ATP is used by enzymes and structural proteins in many cellular processes such as biosynthetic reactions, motility and cell division. One molecule of ATP contains three phosphate groups and is produced by a wide variety of enzymes including ATP synthase from adenosine diphosphate (ADP) or adenosine monophosphate (AMP) and various phosphate group donors. There are three main ATP biosynthesis mechanisms:1) substrate-level phosphorylation, 2) oxidative phosphorylation in cellular respiration and 3) photophosphorylation in photosynthesis.

ATP is consumed in metabolic processes as an energy source and converted back into its precursors. So, ATP is continuously reproduced. At any one time, the human body contains just $250 \mathrm{~g}$ of ATP, about the same amount of energy of a single AA battery. The amount of ATP used by a person is about our own body weight each day [27].

From the above discussion, it can be seen that the production of ATP is cellular level bio-processing activity. So if it can be verify that BIEFM have the direct influence on ATP production of humans, then it can be inferred that BIEFM have direct influence on cell's ATP activity and then to prove BIEFM have the influence on cells' bio-processing activities, or cells' biological functions.

There has been a lot of research on ATP [28-30]. However, as far as the authors are aware, there have been limited researches on the effects of electromagnetic fields on ATP, especially, the effects of bio-inspired electromagnetic fields. 
In this section, equipment for measuring ATP for hygiene monitoring is employed to measure ATP of a number of people with and without electromagnetic fields to determine how electromagnetic fields influence ATP levels in people.

\section{4-2- Tests}

To investigate the effects of bio-inspired electromagnetic fields on ATP, some tests have been done. Magnafield ${ }^{\circledR}$ was used to generate bio-inspired electromagnetic signals, as shown in Figure 2. Neogen's AccuPoint Advanced ATP Hygiene Monitoring System and AccuPoint Advanced Surface Samplers were used to measure ATP. This is a handheld device that accurately detects ATP, as shown in Figure 3.

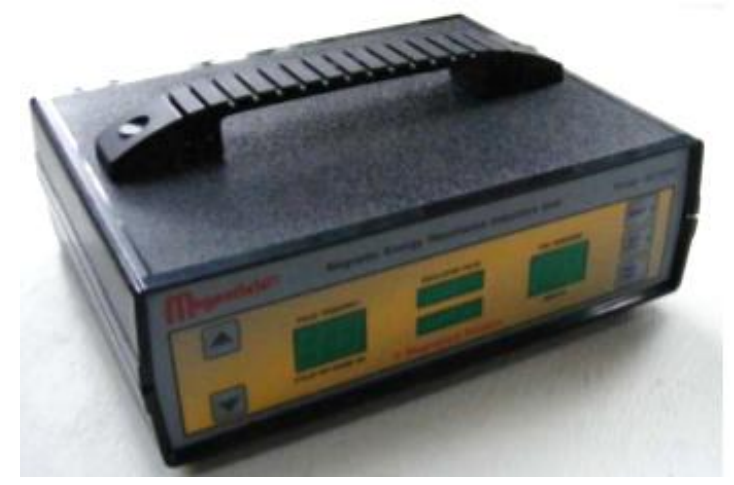

Figure 2. Magnafield $®$ for generating bio-inspired electromagnetic signals.

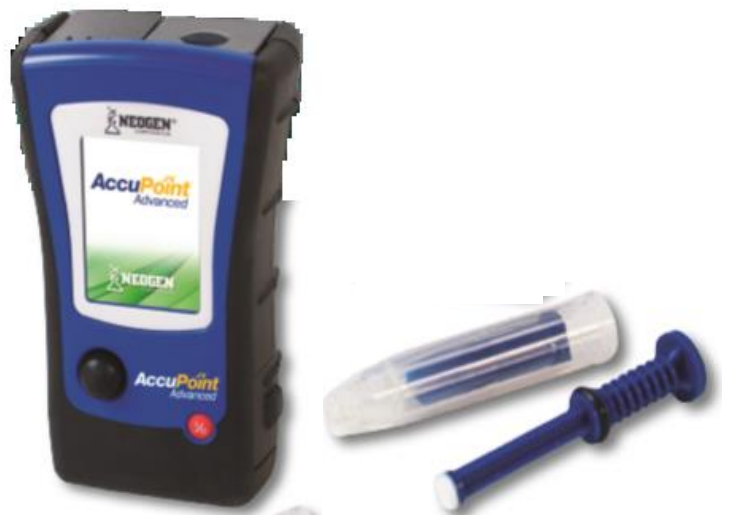

Figure 3. Neogen's The AccuPoint Advanced ATP Hygiene Monitoring System and AccuPoint Advanced Surface Samplers for measuring ATP.

16 people have been invited to join the Test. 8 People are from UK and 8 from China. The age of people is from 15 to 67. There are 14 males and 2 females. They are generally considered as healthy. The disciplines of the people from UK are different from those from China. The people from UK are mainly in sport related discipline while those from China are relatively young students. The other details of the people are listed in Tables 4 and 5. For each people, two times of ATP tests have been carried out. The first time was about 0.5 to 4 hours after diner. The second time test was about 20 minutes after the first time, during this period, the people stay in the bio-inspired electromagnetic fields.

\section{4-3- Test Results}

The Test results are listed in Tables 4 and 5. Table 4 lists the results for the people from UK and Table 5 for the people from China. In the table, $L_{l}$ of Column 5 and $L_{2}$ of Column 6 are the ATP readings for the first time test and the second time, respectively. $\delta L=100 *\left(L_{2}-L_{1}\right) / L_{1}$ of Column 7 is ATP $\%$ increase.

Figures 4 and 5 shows the distribution of ATP \% increase for the two groups with Figure 4 for British group and Figure 5 for Chinese group.

Table 4. The Test results of ATP test for the ten people from UK.

\begin{tabular}{cccccccc}
\hline People & Gender & D.O.B. & Discipline & $\boldsymbol{L}_{\boldsymbol{1}}(\mathbf{R L U} \mathbf{s})$ & $\boldsymbol{L}_{\boldsymbol{2}}(\mathbf{R L U} \mathbf{s})$ & $\boldsymbol{\delta} \boldsymbol{L}=\mathbf{1 0 0 *}\left(\boldsymbol{L}_{\boldsymbol{2}}-\boldsymbol{L}_{\boldsymbol{l}}\right) / \boldsymbol{L}_{\boldsymbol{1}}$ & Date \\
\hline No 1 & F & $07 / 07 / 1995$ & DANCE & 441 & 957 & 117 & $26 / 03 / 16$ \\
No 2 & M & $20 / 01 / 1983$ & BOXING & 192 & 245 & 28 & $26 / 03 / 16$ \\
No 3 & M & $18 / 10 / 1996$ & BOXING & 184 & 842 & 357 & $26 / 03 / 16$ \\
No 4 & M & $02 / 12 / 1996$ & BOXING & 131 & 899 & 586 & $26 / 03 / 16$
\end{tabular}




\begin{tabular}{llllcccc} 
No 5 & M & $08 / 08 / 2001$ & BOXING & 437 & 3213 & 635 & $26 / 03 / 16$ \\
No 6 & M & $14 / 03 / 1996$ & BOXING & 595 & 998 & 68 & $26 / 03 / 16$ \\
No 7 & M & $16 / 03 / 1963$ & BOXING & 772 & 882 & 14 & $26 / 03 / 16$ \\
No 8 & M & $13 / 01 / 1948$ & GOLF & 391 & 873 & 123 & $26 / 03 / 16$ \\
\hline
\end{tabular}

Table 5. The Test results of ATP test for the ten people from China.

\begin{tabular}{|c|c|c|c|c|c|c|c|c|c|}
\hline People & Gender & D.O.B. & Dinner time & Test time & $\begin{array}{c}\text { Time after dinner } \\
\text { (minutes) }\end{array}$ & $L_{1}$ & $L_{2}$ & $\delta L=100 *\left(L_{2}-L_{1}\right) / L_{1}$ & Date \\
\hline No 1 & M & $30 / 08 / 1991$ & $08: 25$ & $10: 10$ & 105 & 1253 & 1751 & 40 & 03/03/16 \\
\hline No 2 & M & 21/08/1989 & $11: 35$ & $15: 00$ & 205 & 974 & 1043 & 7 & $12 / 03 / 16$ \\
\hline No 3 & M & $25 / 03 / 1993$ & $11: 35$ & $16: 00$ & 265 & 328 & 538 & 64 & $12 / 03 / 16$ \\
\hline No 4 & M & 27/11/1992 & 08:00 & $09: 35$ & 95 & 146 & 281 & 92 & $13 / 03 / 16$ \\
\hline No 5 & M & $12 / 12 / 1993$ & $11: 00$ & $15: 50$ & 290 & 268 & 525 & 96 & $13 / 03 / 16$ \\
\hline No 6 & M & 24/04/1992 & $19: 00$ & $20: 20$ & 200 & 412 & 690 & 67 & $13 / 03 / 16$ \\
\hline No 7 & $\mathrm{~F}$ & 01/10/1992 & $08: 20$ & $09: 35$ & 75 & 174 & 869 & 399 & $30 / 03 / 16$ \\
\hline No 8 & M & 16/08/1992 & $11: 30$ & $14: 05$ & 155 & 768 & 1710 & 123 & $30 / 03 / 16$ \\
\hline
\end{tabular}

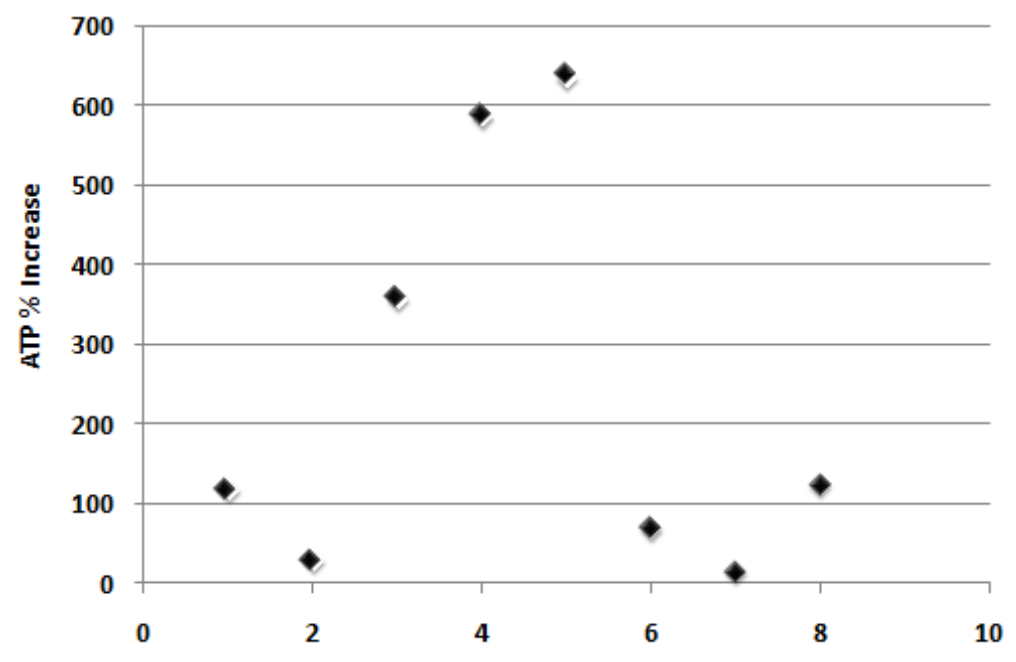

Figure 4. The distribution of ATP\% increase for British group.

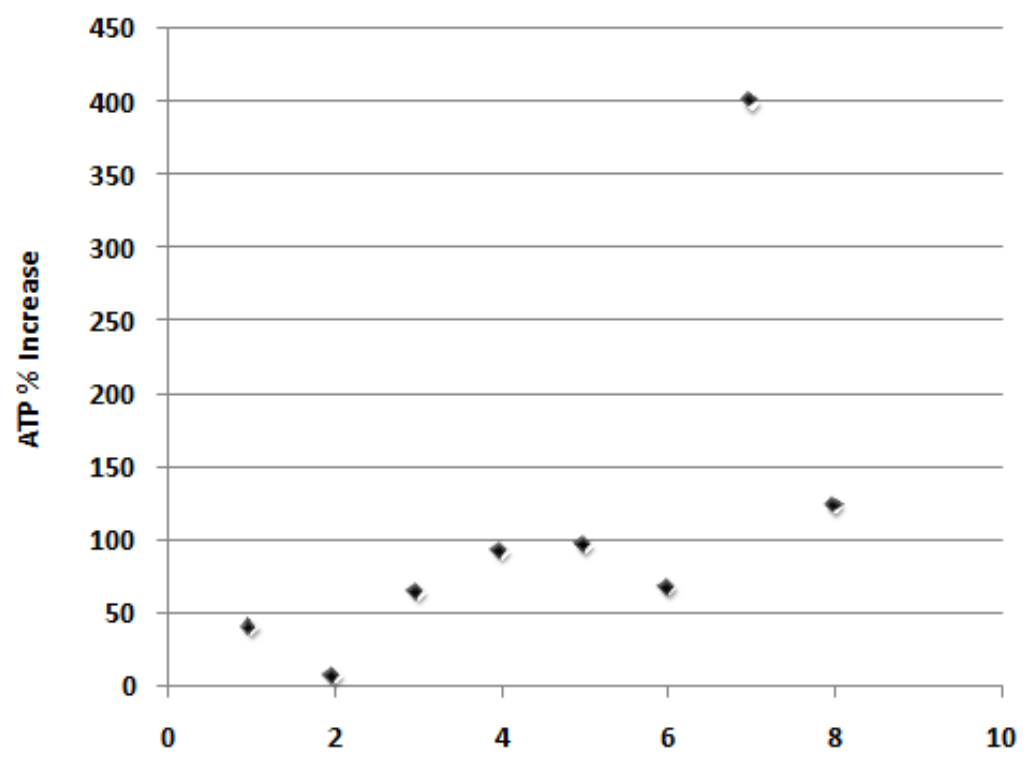

Figure 5. The distribution of ATP\% increase for Chinese group. 


\section{4-4- Analysis and Findings}

From the test results, it can be seen that:

1) Most people's ATP levels have been significantly increased (up to 600\% increase) after they stayed in the bioinspired pulsed electromagnetic field about 20 minutes. The averages of ATP\% increase are $241 \%$ for British group and $111 \%$ for Chinese group. From Figures 4 and 5, it can observed that more people's ATP\% increases are around $100 \%$. That experimentally verifies that the BIPEF do have the significant effects on people's ATP levels. As discussed in Section 4.1, the cellular biosynthesis processes of those people in the BIPEF have been clearly influenced with the positive enhancement.

2) The influences of BIPEF on ATP vary a lot for different people, from as little as $7 \%$ to as large as $635 \%$. This is a very interesting phenomenon. The reasons for this occurrence are possibly that:

(a) The sensitivity of people with different conditions to the BIPEF cannot be the same. It can be reasonably believed that age, health condition, test time from dinner and food quality etc., can all be the factors that are related to the people's sensitivity.

(b) Though the Accupoint ATP monitoring system is one of the most accurate in the world, it is designed specifically to test levels of ATP in samples from any source. The issue facing researchers is not one of equipment accuracy but rather one of sample regularity. Once that issue is resolved then we should see far more accurate readings. There is no question that positive differences are seen using BIPEF it is the accuracy and consistency of sampling that must be addressed. This research is mainly for investigating if there are any influences of the BIPEF on people's ATP, the how accurate the test results are not vital to our findings.

(c) It is believed that this is the first time to study the influences of the BIPEF on people's ATP, so the persons who carried out the test are not experienced to accurately use the AccuPoint Advanced Surface Samplers to collect the test sample. In addition, there are not previous researches on where and how to collect the test samples. When use Neogen's the AccuPoint Advanced ATP Hygiene Monitoring System to test ATP, the amount of the collected sample is very important to obtain consistency of results. After discussions with the experts from Neogen, it was decided that the test samples are collected from the roof of the mouth. From our test practices, it was found that it is very difficult to control the amount of sample collected for different people since the amount of saliva in their mouths are different. To minimise the test errors, the people were asked to rinse their mouth before the test.

d) From Table 5, it can be noticed that though there is not a strong correlation between the datasets of Columns 6 and 9, it is very reasonably convinced that the duration time from dinner to the test seems to plays a considerable role in ATP increase. For example, from Chinese group, the biggest ATP\% increase was with the person who has shortest duration time (75 minutes via 399\%). These findings conform to the theory of ATP generation, as discussed in Section 1.

e) From Table 4, it can be noticed that No.5 (youngest, at 15 years old) has the biggest ATP\% increase (635\%). Though it cannot be proved that the test results are very accurate, it is comfortable to conclude that age plays a role as well in ATP increase. It is possible that the cells are more active and hence more sensitive to the external excites of the BIPEF.

3) The results of ATP tests have shown that BIEMF do have influences on cellular bio-processing activity.

\section{5- Experiments of Effectiveness of Bio-inspired Electromagnetic Field System for Health Enhancement - Magnafield ${ }^{\circledR}$ - Case Studies}

This section presents a number of case studies to experimentally validate the effectiveness and efficiency of this innovative bio-inspired. the case studies include: (1) human health enhancement and illness treatment, (2) pet health enhancement, (3) reduction or elimination of jet lag.

\section{5-1- Human Health Enhancement and Illness Treatment}

\section{5-1-1- Case 1}

Name: Wendy Pearson; Age: 56 years old; Gender: Female; Healthy Problem: Psoriasis of the hands.

Effectiveness: In her own words: 'I have suffered from this condition for more than 40 years, as shown in Figure 6A. The images tell a better story than I can. I used the Magnapulse on an $8 \mathrm{~Hz}$ setting for 4 months and the results can be seen, as shown in Figure 6B. My condition has almost cleared up completely which is nothing short of a miracle'. 




A


B

Figure 6. The hands' conditions before and after using the Magnapulse on an $8 \mathrm{~Hz}$ setting.

\section{5-1-2- Case 2}

Name: Maureen Loseby; Age: 63 years old; Gender: Female; Healthy Problem: Chronic back pain for the last 20 years.

Effectiveness: Maureen was on strong pain killers in order for her to manage the severe back pain condition she had. As a public house landlady her duties were varied and many including standing for long periods of time behind her bar. Strong pain killers were the only method that helped her control the severe back pain she had to endure.

Maureen began using a Magnapulse at settings $8 \mathrm{~Hz}$ and $16 \mathrm{~Hz}$ depending on the severity of her pain. Within two days she had stopped taking pain killing drugs and her pain had diminished to the point where she was able to move freely in little or no discomfort. In her own words:

"I have no idea how the unit works, I only know that it does. You have given me my life back and made an old lady very happy"

Maureen started using the unit 6 months ago and is still pain free today.

\section{5-1-3- Case 3}

Name: Jim Turner; Age: 48; Gender: Male; Healthy Problem: The fast growing face cancer.

Effectiveness: Jim Turner, from San Antonio Texas, is a New York Times Best Selling Author of detective stories. He writes as James Houston Turner. He used to live in Adelaide, but went back to the US about 4 years ago.

In $1991 \mathrm{Jim}$ was diagnosed with a fast growing face cancer. Doctors operated and removed part of his face, neck and shoulder. He came to Magnacare in very poor condition and started using a Magnafield. When he returned to Texas he took the smaller Magnapulse with him as well. On the morning of his departure back to the United States he made this comment:

"You don't beat cancer fighting hard ... you beat it fighting smart.

Here I am on my $24^{\text {th }}$ anniversary of the diagnosis that originally gave me 18 months to live. Some of you have stood by me all the way, especially my gorgeous wife Wendy. Thanks must also go to Magnacare and their amazing products the Magnafield and Magnapulse ... they seriously help!!"

Jim has a zero wheat and sugar diet. He eats a lot of fresh vegetables and very little meat.

\section{5-1-4- Case 4}

Name: April Steiner Bennet; Gender: Female; Healthy Problem: tibia bone broken 
Effectiveness: 'The Magna Pulse should be called magic pulse! With x-ray documentation on my tibia showing the stress fracture, in October, 2017, had now turned into an inflamed crack/separation in the bone, My Personal Trainer was really concerned I was weeks away from a broken leg. I found MagnaPulse and Professor Michael Clark a couple weeks after that and immediately started using it. 5 weeks later, the crack was filling in! I thought my mind was playing tricks, knowing how badly I was praying that I had found the right healing element. But it was not, and 12 weeks from day one of MagnaPulse, It's almost unrecognizable on an x-ray!

I am incredibly grateful for this biomedical technology! There is no doubt in my mind, without MagnaPulse, I would still have a crack in the tibia, be seeking surgery and never be unable to run, jump and bounce around in the same capacity again. It has given me hope for maybe another Olympic Trials but more, it is a tool I will have in my back pocket for any ailments I might encounter in my life'.

\section{5-1-5- Case 5}

\section{Name: LAURIE TRAPP; Gender: Female; Healthy Problem: a tibia plateau fracture}

Effectiveness: "I suffered a bad tibia plateau fracture while mountain biking in early August 2016. I also had cartilage damage from the accident - a quarter-sized flap of cartilage lifted off the tibia surface at the knee (this was over the area that was smashed). My surgeon used a plate and 6 screws, along with cement, to fix it. He said from the beginning that he had never taken hardware out before 8 months of healing. I used the Magnapulse faithfully as much as I could every day (just strapped it onto my leg and left it on 24/7). I had my x-rays and check-ups monthly, and in November my surgeon told me "I can't believe I am saying this, but you can have your hardware out in December, your leg looks THAT good!" My hardware was removed in mid-December 2016, at 4 months, and I have returned to all my previous activities with no restrictions (at a point when most patients are just barely walking again). This rapid recovery was such a blessing to me - I am a chiropractor, and it is such a physical job! But this was the best news of all - when I had my December surgery to remove the hardware, my doctor got a good look at everything. He saw that the loose flap of cartilage had reattached itself and was perfectly healthy - a miracle in itself! Thank you Professor Clark!"

\section{5-1-6- Analysis}

The case studies presented above were chosen specifically because of the differences in conditions and give good examples of the wide range of issues that BIEMF can deal with successfully. These case studies also highlight the important fact that BPEMF is not condition specific. BPEMF based on natural ULF's and ULP reinvigorates the poor condition of cells encountered and by rectifying and enhancing that poor condition helps the body to better combat the root cause of the problem. Because the action of BPEMF is based on natural frequencies and power levels no harm is done. If humans walked bare foot on the natural earth (Grass) they would receive earth based natural frequencies with no harmful effects. BPEMF is no different because it mimics natural processes.

\section{5-2- Small Animal Health Enhancement and Illness Treatment}

In this case study, the Magnafield has been used to help quick recovering post operation and reducing the symptoms due to brain tumors. The test was carried out by Dr Roger Clemmons, and Dr Simon Platt's team at Department of Small Animal Clinical Science, College of Veterinary Medicine, University of Florida.

Dr Roger Clemmons, Dr Simon Platt's team have been using the Magnafield for the three months on several types of clinical cases. To date, they have only used the BIEFM on dogs in the hospital. They have used the unit mostly in acute paraplegic dogs that have spinal cord injuries from herniated intervertebral discs. Because they only have one unit at this stage, and they receive between 2-6 cases of this problem per week, they have been using the Magnafield in the immediate post-operative period on $0.5 \mathrm{~Hz}$ - Repeat mode for at least 24 hours. The length of time will vary depending on how many other cases they have that may need this type of therapy. Their test results have shown that the Magnafield's pulsed electromagnetic field therapy (1) reduces post-operative pain and anxiety and eliminates the need for drug therapy which has the secondary effects that prolong recovery time, (2) has the positive benefits on spinal cord healing after treatment and help the dogs that had brain tumors become quiet, calm and would sleep.

In their own words:

'Typically dogs receive morphine for pain immediately post operatively with repeat morphine every 4-6 hours, as well as oral diazepam to reduce muscle spasms. With this type of drug therapy, dogs are sedated and disoriented for 1218 hours post operatively. Many dogs are still anxious and appear distressed even on this drug therapy'.

Although they can only at this point in time give our clinical observations, they have been impressed with the immediate post-operative recovery of dogs receiving the treatment with the Magnafield. In this study, they still often give one dose of morphine immediately post-operative, but no other drugs. Within 3-4 hours the dogs are awake and responsive and appear relaxed. They think BIEMF reduces post-operative pain and anxiety and eliminates the need for drug therapy which has the secondary effects that prolong recovery time. 
They have used the Magnafield at $0.5 \mathrm{~Hz}$ on Repeat mode, on two dogs that had brain tumors and were delerious, barking and hyperative. They were in the intensive care unit and were disturbing the other animals and staff. Normally, they would have had to sedate them heavily. With the Magnafield, they became quiet, calm and would sleep.

\section{5-3- Reduction or Elimination of Jet Lag}

\section{5-3-1- Introduction}

In this case, the Magnapulse has been used for the people on long flights. It has been found that the effects of 'Jet Lag' on long haul flights can be minimised substantially. The provision of the important $7-8 \mathrm{~Hz}$ bio-inspired pulsed electromagnetic field frequency at the same intensity and power levels found naturally will greatly minimise the effect of 'Jet Lag' if not combat it entirely. The devices have been tested successfully on flights from London to Honolulu, London to Auckland, London to Malé (Maldives) and from London to Hong Kong, Amsterdam to Beijing and Frankfurt to Shanghai both ways. On each occasion there was no or small reported 'Jet Lag' effect either way. The LondonHonolulu and London - Hong Kong flights have been tested 3 times and Amsterdam - Beijing flights, six times, each time with no reported 'Jet Lag'.

\section{5-3-2- Analysis}

Ever since jet lag became a reported phenomenon at the end of long haul flights and in the days that followed, the causes were believed to have their origins in the time differences between embarkation and destination. The most accepted reason is the disruption of 'Circadian Rhythms'.

Circadian rhythms are physical, mental and behavioural changes that roughly follow a 24-hour cycle, responding primarily to light and darkness in an organism's environment. They are found in most living things, including animals, plants and many tiny microbes. The study of circadian rhythms is called chronobiology.

It believed that our biological clocks drive our circadian rhythms. The biological clocks that control circadian rhythms are groupings of interacting molecules in cells throughout the body. A "master clock" in the brain coordinates all the body clocks so that they are in synch. The 'Master Clock' that controls circadian rhythms consists of a group of nerve cells in the brain called the suprachiasmatic nucleus, or SCN. The SCN contains about 20,000 nerve cells and is located in the hypothalamus, an area of the brain just above where the optic nerves from the eyes cross.

Jet lag is said to occur when travellers suffer from disrupted circadian rhythms. When you pass through different time zones, your body's clock will be different from your wristwatch. For example, if you fly in an airplane from London to Beijing, you 'lose' 8 hours of time. So when you wake up at 9:00 a.m., your body still thinks it's 1:00 a.m., making you feel groggy and disoriented. Your body's clock will eventually reset itself, but this often takes a few days, for some people, it can be as long as two weeks.

The body's internal biological clock controls the body's Circadian Rhythms. In turn the biological clock has a strong relationship with the earth's natural magnetic fields (a kind of PEMF). Anything that disrupts the essential influences of the earth's naturally produced magnetic fields, particularly in the 7-8Hz range, will affect the body's internal biological clock and subsequently the body's circadian rhythms.

Any commercial high flying aircraft is in essence a pressurised Faraday cage. It is believed that on short flights of up to and including 6 hours duration and 2 hours' time difference either way should not affect the passenger adversely. If the flight time and time difference between embarkation and destination exceeds 6 hours and 2 hours then an adverse effect will be noticed. The longer the flight and time difference the greater the effect of 'Jet Lag'. Because the aircraft is in essence a sealed and pressurised structure, the long haul passenger will be deprived of the essential life and health giving Schumann frequencies provided by the planet at both ground and high atmospheric levels. ${ }^{9}$ They will get 'Jet Lag' as a result of this deprivation. The severity of the condition will depend on the health of the individual and the length of time in the aircraft. The healthier they are the less they will feel the 'Jet Lag' effects. But they will feel it in some measure!

In addition, the reduced oxygen in the flight also have an effect. Normally, commercial airlines reduce the amount of oxygen in the cabin to reduce fire risk and the obvious cost of the oxygen. This lowered oxygen content in the breathable atmosphere of the cabin also adds to the 'Jet Lag' effect as the body needs full oxygenation of the circulatory system to function correctly. Lowered oxygen levels for the duration of even a $20+$ hour flight is not life threatening but it does have an effect on the passenger which can manifest itself as a component of 'Jet Lag'.

If a passenger wear a Magnapulse at 7-8 Hz, this device will create a local bio-inspired pulsed electromagnetic field round the passenger. This field functions like natural electromagnetic field with Schumann frequencies, then the passenger stay in the environment that is similar to that on the earth. So the effects of by the flying aircraft's pressurised Faraday cage on the passengers will be minimised. Besides, the bio-inspired electromagnetic fields also stimulate ATP production, recharge and balance of ionic and cell membrane potentials. The circulatory oxygen is also improved by the Magnapulse adding to the positive effect of the unit on the effects of 'Jet Lag'. 


\section{6- Conclusion}

This paper presents an innovative bionic system that can be used to generate BIEMF by mimicking natural Earth, the frequencies, strengths and waveforms of body organs and cellular pulsations. The ATP test results show that BIEFM do have the direct influences on the ATP levels of people and hence the cellular level's bio-processing activities.

This innovative bio-inspired system has been applied for health enhancement of humans and pets etc. A number of case studies have been present to demonstrate the efficiency and effectiveness of the system, including (1) human health enhancement and illness treatment, (2) pet health enhancement and (3) reduction or elimination of 'jet lag'. The experimental results of case studies show that this innovative bio-inspired system works efficiently and effectively in enhancing human and animal health.

However, results obtained from the use of BIEMF can and will vary as no two people are the same. Every individual responds in a different way. The current limitation of this research is that (1) the data collection of the case studies does not follow a standard to ensure the consistency of the data collected, (2) the theoretical research on the working principle of the BIEMF is very limited, (3) though the frequency choices of the existing system design are based on the bioinspirations of natural Earth, the frequencies, strengths and waveforms of body organs and cellular pulsations, the study has not covered the details for different organs and different health problems. So it is suggested that further research is carried out to solve these problems.

\section{7- Conflict of Interest}

The author declares that there is no conflict of interests regarding the publication of this manuscript. In addition, the ethical issues, including plagiarism, informed consent, misconduct, data fabrication and/or falsification, double publication and/or submission, and redundancies have been completely observed by the authors.

\section{8- Ethical Approval}

All procedures performed in studies involving human participants were in accordance with the ethical standards of the institutional and/or national research committee and with the 1964 Helsinki declaration and its later amendments or comparable ethical standards.

\section{9- References}

[1] Maton, A., D. Lahart, J. Hopkins, M. Q. Warner, S. Johnson, and J. D. Wright. "Cells: Building Blocks of Life.", New Jersey: Prentice Hall, (1997).

[2] Veksler, Alex, and Nir S. Gov. "Calcium-Actin Waves and Oscillations of Cellular Membranes." Biophysical Journal 97, no. 6 (September 2009): 1558-1568. doi:10.1016/j.bpj.2009.07.008.

[3] Adey, W. Ross. "Biological Effects of Electromagnetic Fields.” Journal of Cellular Biochemistry 51, no. 4 (April 1, 1993): 410416. doi:10.1002/jcb.2400510405.

[4] Joshi, R. P. "Pulsed Electric Fields in Biological Cells and Membranes.” Electromagnetic Fields In Biological Systems (2016): 87-130. doi:10.1201/b11257-6.

[5] Hand, J.W. and Cadossi, R., Therapeutic applications of electromagnetic field in: The review of Radio Science 1990-1992, edited by W. Ross Stone, (1993): 779-796.

[6] Ueno, Shoogo. "Static, Low-Frequency, and Pulsed Magnetic Fields in Biological Systems." Electromagnetic Fields In Biological Systems (2011): 131-212. doi:10.1201/b11257-7.

[7] Skupin, Alexander, Helmut Kettenmann, Ulrike Winkler, Maria Wartenberg, Heinrich Sauer, Stephen C. Tovey, Colin W. Taylor, and Martin Falcke. "How Does Intracellular Ca2+ Oscillate: By Chance or by the Clock?" Biophysical Journal 94, no. 6 (March 2008): 2404-2411. doi:10.1529/biophysj.107.119495.

[8] Paluch, Ewa, Matthieu Piel, Jacques Prost, Michel Bornens, and Cécile Sykes. "Cortical Actomyosin Breakage Triggers Shape Oscillations in Cells and Cell Fragments.” Biophysical Journal 89, no. 1 (July 2005): 724-733. doi:10.1529/biophysj.105.060590.

[9] Lipkova, J., and J. Cechak. "Human electromagnetic emission in the ELF band." Measurement Science Review 5, no. 2 (2005): 29-32.

[10] Jones, D. “Extremely Low Frequency (ELF) Ionospheric Radio Propagation Studies Using Natural Sources.” IEEE Transactions on Communications 22, no. 4 (April 1974): 477-484. doi:10.1109/tcom.1974.1092214.

[11] Guyton, C. and Hall, J., Textbook of Medical Physiology, Twelfth edition, ISBN: 978-1-4160-4574-8, International Edition: 978-0-8089-2400-5, (2011).

[12] Lin, J. C., Electromagnetic Fields in Biological Systems (Biological Effects of Electromagnetics) (Hardcover), 1 st Edition. ISBN-10: 143985999X ISBN-13: 978-1439859995, (2011). 
[13] Frey, A H. "Electromagnetic Field Interactions with Biological Systems.” The FASEB Journal 7, no. 2 (February 1993): 272281. doi:10.1096/fasebj.7.2.8440406.

[14] Phillips, J. L., and L. McChesney. "Effect of $72 \mathrm{~Hz}$ pulsed magnetic field exposure on macromolecular synthesis in CCRF-CEM cells." Cancer biochemistry biophysics 12, no. 1 (1991): 1-7.

[15] Walleczek, J. "Electromagnetic Field Effects on Cells of the Immune System: The Role of Calcium Signaling." The FASEB Journal 6, no. 13 (October 1992): 3177-3185. doi:10.1096/fasebj.6.13.1397839.

[16] Oschman, J., "Energy Medicine, The Scientific Basis", 2nd Edition, Elsevier (2016).

[17] Midura, Ronald J., Michael O. Ibiwoye, Kimerly A. Powell, Yoshitada Sakai, Todd Doehring, Mark D. Grabiner, Thomas E. Patterson, Maciej Zborowski, and Alan Wolfman. "Pulsed Electromagnetic Field Treatments Enhance the Healing of Fibular Osteotomies.” Journal of Orthopaedic Research 23, no. 5 (September 2005): 1035-1046. doi:10.1016/j.orthres.2005.03.015.

[18] Bassett, C. A. "Fundamental and practical aspects of therapeutic uses of pulsed electromagnetic fields (PEMFs)." Crit Rev Biomed Eng 17, no. 5 (1989): 451-529.

[19] Frey, Allan H., and Elwood Seifert. "Pulse Modulated UHF Energy Illumination of the Heart Associated with Change in Heart Rate.” Life Sciences 7, no. 10 (May 1968): 505-512. doi:10.1016/0024-3205(68)90068-4.

[20] Walleczek, Jan, and Robert P. Liburdy. "Nonthermal 60 Hz Sinusoidal Magnetic-Field Exposure Enhances 45 Ca2+ Uptake in Rat Thymocytes: Dependence on Mitogen Activation." FEBS Letters 271, no. 1-2 (October 1, 1990): 157-160. doi:10.1016/0014-5793(90)80396-z.

[21] Marchionni, I., A. Paffi, M. Pellegrino, M. Liberti, F. Apollonio, R. Abeti, F. Fontana, G. D'Inzeo, and M. Mazzanti. "Comparison Between Low-Level $50 \mathrm{~Hz}$ and $900 \mathrm{MHz}$ Electromagnetic Stimulation on Single Channel Ionic Currents and on Firing Frequency in Dorsal Root Ganglion Isolated Neurons.” Biochimica et Biophysica Acta (BBA) - Biomembranes 1758 , no. 5 (May 2006): 597-605. doi:10.1016/j.bbamem.2006.03.014.

[22] Haarala, Christian, Sargo Aalto, Hubertus Hautzel, Laura Julkunen, Juha O. Rinne, Matti Laine, Bernd Krause, and Heikki Hämäläinen. "Effects of a $902 \mathrm{MHz}$ mobile phone on cerebral blood flow in humans: a PET study." Neuroreport 14, no. 16 (2003): 2019-2023.

[23] Krause, Christina M., Lauri Sillanmäki, Mika Koivisto, Anna Häggqvist, Carina Saarela, Antti Revonsuo, Matti Laine, and Heikki Hämäläinen. "Effects of electromagnetic field emitted by cellular phones on the EEG during a memory task." Neuroreport 11, no. 4 (2000): 761-764.

[24] Gordon, R.T., and D. Gordon. "Selective Resolution of Plaques and Treatment of Atherosclerosis by Biophysical Alteration of 'cellular' and 'intracellular' Properties." Medical Hypotheses 7, no. 2 (February 1981): 217-229. doi:10.1016/03069877(81)90118-3.

[25] Rich, P. R. "The molecular machinery of Keilin's respiratory chain." Biochemical Society Transactions (2003): 1095-1105. doi:10.1042/bst0311095.

[26] Tornroth-Horsefield, S., and R. Neutze. "Opening and Closing the Metabolite Gate." Proceedings of the National Academy of Sciences 105, no. 50 (December 10, 2008): 19565-19566. doi:10.1073/pnas.0810654106.

[27] Hardie, D. Grahame, and Simon A. Hawley. "AMP-Activated Protein Kinase: The Energy Charge Hypothesis Revisited." BioEssays 23, no. 12 (2001): 1112-1119. doi:10.1002/bies.10009.

[28] Beutler, Ernest, and Claramma K. Mathai. “A Comparison of Normal Red Cell ATP Levels as Measured by the Firefly System and the Hexokinase System.” Blood 30, no. 3 (September 1, 1967): 311-320. doi:10.1182/blood.v30.3.311.311.

[29] Boyer, Paul D. “A Research Journey with ATP Synthase.” Journal of Biological Chemistry 277, no. 42 (August 13, 2002): 39045-39061. doi:10.1074/jbc.x200001200.

[30] Mikirova, Nina, Hugh D. Riordan, R. K. Kirby, A. Klykov, and James A. Jackson. "Monitoring of atp levels in red blood cells and $t$ cells of healthy and ill subjects and the effects of age on mitochondrial potential." Journal of Orthomolecular Medicine 20, no. 1 (2005): 50-58. 